\title{
Public Policy and Network Governance in Ghana: Challenges for Urban and Regional Development
}

\section{Misharch Osei}

Environment and Natural Resources, Albert-Ludwigs-Universitat Freiburg, Germany

"Corresponding author: Misharch Osei, Environment and Natural Resources, A Ibert-Ludwigs-Universitat Freiburg, Germany, Tel: +4915216094648; E-mail: misharch08@yahoo.com

Received date: September 27, 2018; Accepted date: October 02, 2018; Published date: October 08, 2018

Copyright: (C) 2018 Osei M. This is an open-access article distributed under the terms of the Creative Commons Attribution License, which permits unrestricted use, distribution, and reproduction in any medium, provided the original author and source are credited.

\begin{abstract}
Does network governance really work? And what difference does network governance make in promoting sustainable environmental governance? How can the performance of network governance be determined? And what factors contribute to success and failure? This study evaluates the performance of network governance on contemporary and future governance arrangements in environmental governance. The study primarily relied on the small-N qualitative methods of data collection through series of semi-structured interviews with key stakeholders primarily network participants', national and regional level government officials involved the selected governance networks, district level officials and local elected politicians, non-governmental organizations' [NGOs] actors and traditional authorities at the districts and local sites. The analysis presented here, however, demonstrates the relative network governance effectiveness is highly contextual and contingent on the problem involved. The findings demonstrate governance network is most likely to be effective in cases where the problems faced to be addressed are complex, multi-faceted, and resource demanding such as slum upgrading, pollution, and land degradation. The study also found that governance networks are more likely to be effective in cases where there are clear positive incentives such as provision of government funding, donor supports, and or negative incentives such as peer pressure or regulatory defaults. Additionally, measures to reduce transaction costs and decision rules that foster consensus building are vital to the effectiveness of governance network. However, in the light of the chronic hierarchical and market based mechanisms resource management deficiencies in Ghana, epitomized in the urban environment and land resource sectors, bringing public, private, and civil-society actors together for frank political debates on resource governance is becoming urgent. It is argued that doing so requires addressing the restraints regarding the role of traditional authorities in resource governance will improve the social and environmental performance of land resource and mining activities in the country.
\end{abstract}

Keywords: Ghana; Network governance; Network performance; Hierarchical governance; Market-based governance

\section{Background to the Study}

Governance networks are today emerging in Ghana. By bringing private, public, civil-society, and other non-state actors together, the aim is to enhance the production of efficient and legitimate policy goals and policy outcomes. However, the current nature of political processes calls for empirical assessment of the actual performance of network governance with respect to the sources and mechanisms of network governance performance, and under which conditions do we find failure and success. With the increasing failure of state-led ${ }^{1}$ and market-based mechanisms ${ }^{2}$ in addressing complex interconnected environmental problems, networking governance has been recognized to have the capacity to address complex multi-faceted environmental issues globally. Network governance ${ }^{3}$ has attained popularity and recognition the communities of environmental governance literature and the public policy discourses in recent years for its capacity in pursuing multiple strategies to address complex and inter-connected problems. The same can be said in delivering human services and addressing environmental issues at both local and regional levels [1]. Several lines of reasoning as to why and how network governance provides innovative platforms for addressing environmental issues have been extensively identified in the literature $[1,2]$.

Within the transaction cost theoretical framework, network governance is considered as an intermediate form of governance between markets and hierarchies, which allow actors to react flexibly to complex, inter-connected uncertain and changing environmental issues compared to hierarchies while being more reliable and stable

$1 \quad$ This describes the traditional hierarchical dominant-agency mechanisms through regulatory agencies to address range of persistent environmental issues.

2 This describes the use market instruments like the use of both positive and negative incentives, levies, and taxes to address complex persistent environmental issues.

3 Governance network describes "a stable articulation of mutually dependent, but operationally autonomous actors from state, market and civil society, who interact through conflict-ridden negotiations that take place within an institutionalized framework of rules, norms, shared knowledge and social imaginaries; facilitate self-regulated policy making in the shadow of hierarchy; and contribute to the production of 'public value' in a broad sense of problem definitions, visions, ideas, plans and concrete regulations that are deemed relevant to broad sections of the population" (Sørensen and Torfing 2009: 236). 
than markets. Network governance is more likely to be effective in policy settings where negotiated solutions among stakeholders are seen as appropriate and necessary, and thus where technical solutions are not possible. It permits different sources of competences and knowledge provided by the different stakeholders to be integrated, especially when the network arrangement fosters efficient social learning and information sharing [2].

Subsequently, there is euphoric praise of the capacity of network governance in addressing modern multi-faceted societal developmental problems. With its increased prominence and countless publications about its suppose success, the actual performance of network governance has received little attention in literature [3]. The concern about network governance performance has been raised in recent years, due in part to a series of highly publicized network failures $[3,4]$. Provan and Kenis have emphasized the need to assess the actual performance of network governance since the literature at the moment lack very empirical evidence to support the euphoric praise of network governance compared to the volumes of publications on the performance of single actors or groups of actors within network governance [5]. Moreover, the conditions under which we can account for the success or failure in network governance process is underresearched, leaving the question of what is successful network governance and how to evaluate failure still open and unanswered. The study aims to bridge this gap in the literature by evaluating the actual performance of network governance. The qualitative case study approach was used to compare two mega network governance projects in environmental sector of Ghana.

\section{Statement of Research Questions}

The performance of network governance has been questioned in recent years. Bob Jessop for example, has drawn our attention to the fact that network governance can fail to deliver like other modes of governance [6]. Researchers and policy analysts have overtime overlooked the possible risks involved in substituting network governance for hierarchical or market failure and the resulting possible network failure [6]. Klijn and Koppenjan also questioned the performance of network governance [7]. According to them, the positive picture of network governance epitomizes has been extensively highlighted in the literature. However, the biggest limitation is lack of adequate and clear conditions and mechanisms that account for the actual performance of network governance and the conditions under which we can find 'success' or 'failure'.

The problem is further compounded since networks bring to the table a diversity of stakeholder views and thus diverse perspectives about processes, goals, and outcomes. How do we assess the performance of governance network under these conditions of negotiated processes objectives, with complex causal pathways? The deficits and limitations in the literature made this study critical and important research topic both to governments,' policy analysts, and practitioners. The study sought to examine the mechanisms that affect the performance of governance network with the aim of identifying the conditions that account for success or failure. The question that then arises is what are the sources and mechanisms of network governance performance and what factors contribute to success and failure? In order to address this central research question, the following subquestions were formulated;

- What are the conditions essential for possible cooperation in governance network?
- What kinds and levels of participation necessary for effective governance process?

- How and to what extent those better resourced and well placed participants such as elected officials and industry players influence the decision-making process?

- To what extent the decisions and policies that go on in PSUP and GRMA projects are made subject to accountability?

- How, when, and to what extent the stakeholders/participants can gather, analyze, learn on information on their progress in practice?

These questions were addressed by means of comparative evaluative case study of the Participatory Slum Upgrading Project (PSUP) and Ghana Responsible Mining Alliance (GRMA) in Ghana. In addressing the research questions the analyses were mainly based on the stakeholders' perception on the performance and progress of the network and the conditions that have contributed to their success or otherwise.

\section{Study Objectives}

The main purpose of this study was to assess the actual performance of network governance with the aim of identifying the conditions that account for success or otherwise. The study uses two case studies which main focus is on promoting good environmental governance. Other related objectives included; providing deep insights to the government about how to organize network governance, and what the limitations are of relying on networks. The study also aimed to reveal to the stakeholders and network participants analyzed how the networks functions and what the relative position is of the participants involved affect the overall outcome of the alliance. Another objective was to increase our understanding procedural conditions that affect the processes in building successful network governance, hence the need to compare the two cases to illuminate the variations in degrees building successful network. In other words, what procedural and institutional reasons for account for these variations? In doing so the study intended to provide an updated review of the conditions and mechanisms that affect the governance network effectiveness.

Subsequently, the analyses were substantially based on the sustainability of good processes (i.e. whether good processes have been embedded for building sustainable results) at the network level. The study was limited to assessing only the sustainability of good process because the empirical cases under investigation were all relatively new and as such environmental outcomes and ex-ante performance of governance networks typically take long period of time to be manifested; hence it was too early to be able to assess outcomes. Hence, this present study did not cover outcome-oriented performance since such assessment would require before and after data, and with the empirical cases such data were lacking. This outcome-oriented performance were therefore not included in this study on the premise that such outcomes may not easily be assessed as they are influenced by multiple factors and actors besides the activities of the stakeholders in PSUP and GRMA projects.

\section{Research Approach: Evaluation Research}

Evaluating the performance of network is an important task since networks are often set up to create certain values for society; therefore their performance should be assess at some point to find out whether they contribute to fulfill these ambitions. Evaluation research normally seeks to examine and judge processes and outcomes of intervention attempts aimed at solving problems or bringing about change in 
Page 3 of 8

society [8]. Two main types of evaluation research can be identified in the network governance literature. These are 'formative' and 'summative' evaluations [8]. The purpose of summative evaluations has always been to assess the overall performance of an intervention program whereas formative evaluations tend to focus on formulating policy recommendations on the basis of which an intervention program can be improved. In addition, summative evaluations can be generalized to future efforts and to other programs, the usefulness of formative evaluations is limited to the specific setting studied [8]. The main purpose of this study is to evaluate the overall of network governance; this study was situated within the summative evaluation research.

In carrying out this summative evaluation research the small-N qualitative methods of data collection was utilized. Primary data was collected through semi-structured interviews with twenty-six key stakeholders primarily network participants', national and regional level government officials involved the selected governance networks, district level officials and local elected politicians, non-governmental organizations' (NGOs) actors and traditional authorities at the districts and local sites. Insights from published materials and policy documents were also consulted. The purposive sampling technique was used to select participants to be included in the study based on their knowledge and information about the existence, functioning and operations of the network. Upon the first official meeting with the organizations, author was lucky to identify appropriate participants to be included in the study. All participants were approached to participate in the research voluntarily and received some explanation about the purpose of our research. Author told them officially that there were no right or wrong answers to the questions, and that they could withdraw from the study at any point without reason and that their names would not be used anywhere in our research, unless they willingly asked for it. Author has always been completely open about the intention of our research to participants and this motivated them to provide as much information as possible.

\section{Criteria for Selecting Cases}

This study utilized comparative case study with embedded units of analysis. The goal was to fill the gap in existing studies which have mainly tended to be single case project-related evaluations with limited institutional analysis. Consistent with the network governance theoretical approach, these cases exhibit great variation across a range of variables, the scale of action including their problem focus, mixes and roles of participants, their existence, and policy contexts which makes it appropriate to compare and evaluate their performance. Although other programmes could have been included in the study, given the inevitable time and budget limitations, author focused on these two programmes with the main objective of capturing differences in for example policy domain in which the problems are located, the complexity and challenges of the problem, key stakeholders and roles of network stakeholders, and the functional focus of the collaborative activities. The table below demonstrates the criteria for selecting the two cases (Table 1).

\begin{tabular}{|c|c|c|c|c|}
\hline Cases & $\begin{array}{l}\text { The policy domain in } \\
\text { which the problems } \\
\text { are located }\end{array}$ & $\begin{array}{l}\text { Key stakeholders and } \\
\text { Network scale of action }\end{array}$ & $\begin{array}{l}\text { Funding and Roles of network } \\
\text { Stakeholders }\end{array}$ & $\begin{array}{l}\text { Functional focus of the } \\
\text { collaborative activities }\end{array}$ \\
\hline PSUP Project & $\begin{array}{l}\text { Urban Planning, slum } \\
\text { upgrading, community } \\
\text { development }\end{array}$ & $\begin{array}{l}\text { PSUP included only few } \\
\text { government agency, NGOs and } \\
\text { local residents }\end{array}$ & $\begin{array}{l}\text { Relied mainly on the facilitation and use of } \\
\text { government assisted funds, shared } \\
\text { responsibility in planning, implementation, } \\
\text { and monitoring }\end{array}$ & $\begin{array}{l}\text { Information exchange among } \\
\text { members, policy advice and } \\
\text { advocacy. }\end{array}$ \\
\hline GRMA Project & $\begin{array}{l}\text { Environmental } \\
\text { protection } \\
\text { sustainability, and } \\
\text { capacity building }\end{array}$ & $\begin{array}{l}\text { GRMA involved multiple local, } \\
\text { industry bodies, NGOs and local } \\
\text { citizens. }\end{array}$ & $\begin{array}{l}\text { Relied mainly on members contributions, } \\
\text { government grants, key functions are } \\
\text { administered by the lead organization }\end{array}$ & $\begin{array}{l}\text { Information exchange among } \\
\text { participants, local capacity building, } \\
\text { better planning for land use }\end{array}$ \\
\hline
\end{tabular}

Table 1: Differences among different types of Network Governance.

\section{Theoretical Approach: Network Governance Theory (NGT)}

The study was carried out through the network governance theory (NGT). Proponents of NGT approach argue that public policy-making and implementation increasingly take place within a multi-layered polity, formally organized by governments at central, regional and local levels. At all levels, policy-making involves elected politicians as well as powerful executive administrators. However, it also involves other actors like lower ranking administrators, interest organizations, private and public firms, popular movements and citizen groups [3]. This is what it is termed as governance within and through networks of interdependent, but operationally autonomous actors that are involved in the production of public policy. Network governance describes an inter-organizational medium for interest mediation between autonomous and interdependent, but antagonistic and conflicting actors, each of whom has a resource base of themselves [3].
Networks are mostly formed through the outcome of the strategic actions of independent actors who interact in order to benefit from the resource base (such as knowledge, innovative ideas, funding, formal authority etc.) of other actors to regulate and govern a certain policy sector. According to Sørensen and Torfing decision-making in governance network is based on continuous interaction, compromise and negotiation among stakeholders and consensus becomes possible because of stakeholders' mutual resource dependencies to address public problems which individual actors cannot unless they collaborate [3]. The theory highlights that governance networks are incremental bottom-up processes where politicians strategically select some actors participate in the policy making and implementation process [9]. It is believed governance networks seek and promote different antagonistic interests mainly through the internal power struggle mechanisms, but importantly are held and bound together by their mutual interdependence, which ultimately promote compromise as well as providing a relatively stable environment for negotiation for effective 
and efficient delivery of network goals. Consequently, the theory argue that public policy making are moving towards being intertwined in forms of interactive networks which in many cases are not prescribed by constitutions, legal frameworks and statutes. This proponents call governance networks; they are neither market nor government nor civil society instruments; they are hybrid organizational forms [10]. This study understands network governance as an integration of a number of interdependent, but autonomous actors performing negotiations based on a common understanding of factors like regulation, norms and common perceptions. In that case, networking governance coordinates policy decisions, and to some degree are selfregulating and self-steering [3]. However, there will be some steering or controlling of the networks by central government, and such orchestration will here conceptually be termed meta-governance.

According to Rhodes [9] network governance is flexible and proactive autonomous self-organizing, and self-governing. For these reasons, it has been concluded that network governance in order to succeed require high-level of trust among stakeholders, reputation, mutual interdependence, and reciprocity [9]. Subsequently, network governance provides a reflexive alternative to the procedural rationality of the market and the substantial rationality of the state [6]. In the wake of market and state-controlled instruments failure, network governance rises as a phoenix from the ashes to have the capacity in building platforms for collaborative processes that can contribute to enhance the quality of public policies and delivery public services.

\section{Is Network Governance Panacea for Promoting Sustainable Environmental Governance?}

In the wake of apparent failures to govern complex environmental problems by the central state, networking modes of governance have been proposed in recent years [11]. Network governance is the mode most commonly associated with the concept of governance, in which autonomous actors' work together to achieve common goals (Ibid). The emergence of network governance can be characterized by an attempt to take into account the increasing importance of the private sector, NGOs, scientific networks and international institutions in the performance of various functions of governance. Prominent examples of such networks that have been instrumental in forming successful working arrangements are the Global Environmental Facility, the World Commission on Dams, and the flexible mechanism of the Kyoto Protocol [12]. Another ongoing effort of governance networks in environmental governance is the United Nations Global Compact which combines multiple actors' in a trilateral construction including representatives from governments, private sector and the NGO community to address environmental challenges [13].

Dedeurwaerdere and Haas emphasized that one main reason for the proliferation of network approaches in environmental governance is their potential to integrate and make available different sources of knowledge and competences from different sectors and to encourage individual and collective learning [13,14]. According to Newig et al. [11], environmental governance currently faces various challenges that are characterized by complexities and uncertainties inherent to environmental and sustainable problems. In the view of Head network governance can provide a means to address these governance problems by institutionalizing learning on facts and deliberation on value judgments [14]. A critical example is in the realm of global chemical safety, where transnational networks have formed around initiatives by international organizations and successfully developed rules for addressing global chemical issues many of which have been implemented by national legislations across countries. Most importantly, these transnational networks made it possible to avoid the institutional apathy that is typically found in political settings with many actors of conflicting interests, especially on a global level [11].

According to Dedeurwaerdere through integration of actors from different sectors of society, governance networks are able to provide an innovative environment of learning, providing the way for adaptive and effective governance [13]. One particular characteristic of networks important to solving complex multi-layered environmental problems is its formation of 'epistemic communities' in which actors share the same basic casual beliefs and normative values (Dedeurwaerdere: Although participation in these networks requires stakeholder's interest in the policy problem at stake, the actors involved do not necessarily seek to promote the same interest) [13]. In general, the interests are interdependent but can also be different or sometimes conflicting, emphasizing the need for consensus building and the development of cognitive commodities [11]. The conclusion drawn from previous suggest that the advantage of network governance over traditional state command and control regulations or, alternatively, the use of market instruments, lies in its capacity to deal with situations of intrinsic uncertainty and decision making under bounded rationality [14]. This is typically the case in the field of environmental governance where one has to deal with complex multi-layered and interrelated problems. In these circumstances, network governance can create a synergy between different competences and sources of knowledge from all segments of society allowing dealing with complex and interlined problems $[13,15]$.

\section{Evaluating Network Performance - Conceptual and Theoretical Challenges}

The underlying question in assessing the performance of network governance is whether governance networks make a difference in the quality of service provision and addressing complex public policy issues. In other words, what value emerges from the network-based governance? Provan and Milward identified three levels of analysis for evaluating the performance of network governance involved in community-based health and human services [16]. These elements included; (i) the network as an organization, (ii) the community, and (iii) the organizational participants. They outlined three categories of constituents which need to be considered; "principals, who monitor and fund the network and its activities; agents, who work in the network both as administrators and service-level professionals; and clients, who actually receive the services provided by the network" [16]. According to them the assessment criteria might include a mix of process issues (such as the network survival, membership interaction, network growth, and service co-ordination and outcome issues at different levels, such as impact on clients, range of services, cost effectiveness of services) [16].

In the area of human services provision for disadvantaged societies, Connell et al. and Schorr highlighted the need for rigorous research on the impact of the network programmes on the disadvantaged population groups $[17,18]$. For example, evidence-based programme evaluations using rigorous methods including randomized controlled trials. However, methods such as randomized controlled trials may be misleading and insufficient due to problems such as limited formal knowledge derived from network programme. In this regard, other sources of knowledge are required, because "too many programs are multidimensional, cannot or should not be standardized, evolve or 
adapt through time, require stakeholders' active involvement, or are heavily dependent for success on good implementation, not just good design" [18]. Schorr therefore support the need for more flexible forms of assessment that require researchers to work jointly in pooling their knowledge together.

In relation to addressing complex, inter-connected, multi-faceted environmental issues, network governance has been persistently argued to have the capacity in developing multiple strategies to address a number of inter-connected issues both at the local and regional levels. This has led some scholars using multiple criteria for assessing the performance of network-based projects. Leach for example in their study into the US Watershed Management Initiatives used six types of outputs and outcomes criteria to assess the performances of the initiatives. The criteria they employed included; "the perceived effects of the partnership on specific problems in the watershed; implementation of agreed restoration projects; perceived effects of the partnership on human and social capital; the extent of agreement reached among the stakeholders; collection of data for monitoring the effects of actions taken; and undertaking education and outreach projects" [15]. The limitation however is how can we cautiously prevent any premature judgments being drawn by funders' and public officials since governance networks may take some time to overcome distrust, educate stakeholders, secure funding, reach agreements, and begin implementation.

The reliance on solely the 'satisfaction' expressed by stakeholders as used in previous studies pose great limitations for the reason that such views may be misleading and a poor guide to determine whether enduring benefits are being achieved for the environment. In the view of Coglianese all these highlight the importance of first assessing the sustainability of good process characteristics. It is until recently that Public Administration theorists like Sørensen and Torfing have attempted to assess the performance of governance networks in terms of their ability to effectively modify their competing valid goals and interests in the face of continued disagreement. In their study, they evaluated the performance of governance networks in terms of their ability to deliver their purported benefits in practice $[3,19]$. That is, provide effective and efficient negotiated interactions between a plurality of independent public and private actors to address the policy problems [3].

According to Sørensen and Torfing the success or failure of network governance cannot be prescribed on forehand [3]. In their view the performance of governance networks is believed to be most often dependent on the institutional capacity, deliberative process, and the use of management techniques. Accordingly, the proponents of the governance network theory have emphasized the process of facilitating interaction and cooperation among stakeholders; inclusion and meaning participation of all affected stakeholders; flexible deliberations; horizontal accountability; and mechanisms to enhance learning and institutional memory among the stakeholders to positively influence the building of sustainable good processes in governance network. The study identified these five crucial interconnected variables to affect the performance of PSUP and GRMA sustainability of good processes. Hence, the independent variables used in the study consisted of the factors and conditions the governance network theory postulates could positively or negatively impact on building long-term multi-stakeholder commitments. The five conditions (i.e. independent variables) included; collaboration, participation, deliberation, learning and horizontal accountability. How these variables affect and influence the building of sustainable good process (Performance) of network governance are formulated below (Figure 1).

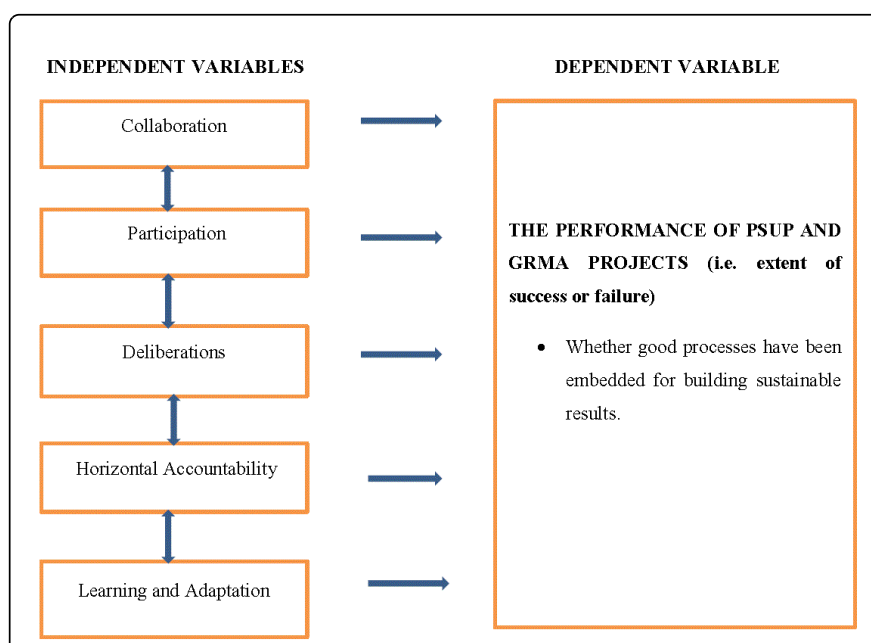

Source: Developed from reviewed literature (June-August, 2014)

Figure 1: Analytical Framework: Linking Independent variables to Dependent variables (Source: Developed from reviewed literature [June-August, 2014]).

\section{Results}

For the purposes of capturing diversity of views to facilitate comparisons between the two networks, the respondents were primarily selected on the basis that they capture the main stakeholder types involved or connected to each of the network programme. Again, due to time and budgetary limitations, it was not feasible to select participants' numbers that specifically reflect the proportion and distribution of stakeholder types in each case under investigation. The key study findings have been structured around the outcomes based on the five evaluative criteria discussed above.

\section{The process of fostering successful collaborative governance}

To enhance collaboration and to improve a sustained environment for all relevant and most affected actors to participate in the deliberation process, governance networks are believed to be design in such a way that it provides in-kind incentive support such as funding to reduce or offset the transaction cost of participating. Like in the PSUPS project, the GRMA designed and initiated through a Memorandum of Understanding (MoU) between the stakeholders. To harness institutional regulation, these MoUs served as an incentive to get affected and relevant participants to participate in the governance process. However, while direct legal regulations remained evident in both networks, the incentive and other persuading mechanisms adopted by the designers in both cases offered a less costly and conflict-ridden environment for actors to come to the collaborative and deliberative table to discuss and negotiate for solutions to public problems. However, GRMA project was able to foster a very sustained and successful collaborative network process than that of the PSUPS. This was mainly attributed to both government financial support and the USAID technical support coupled with the small number of affected residents in the communities reduced the transaction cost for participating, and ensured that the GRMA project capture all relevant and most affected stakeholders (Interview, 2014). The GRMA project 
Page 6 of 8

having engaged all key affected actors who should be at the collaborative and negotiation table fostered easy agreement on plan of action and policy targets to be implemented.

Furthermore, the cooperative approach and high level of trust by local residents in the lead industries helped reduced the transaction cost of negotiating on feasible and implementable targets to ensure and observe responsible mining principles to improve the lives of local residents. Additionally, the existence of high level of trust among stakeholders shortened the time frame it took to negotiate and set targets and the implementation of these targets (Interview, 2014). This improved relationship between the major stakeholders and local residents helped the GRMA project to achieve almost unanimous agreement on the development targets set. This substantial unanimity and consensus on targets was underpinned by the shared trust among stakeholders that each will commit resources to the implementation of plans and the stipulated decision rules in the MoU (Interview, 2014).

In comparative terms, the PSUPS focuses on addressing more complex problems across larger slum areas and involved a greater number of stakeholders than the GRMA project. Contrary to findings from previous studies, the inclusion of greater number of participants in the network should have led to less collaboration than in the GRMA project. However, the initiation and the design process of the PSUPS project brought about some level of trust and awareness as well as sustained collaboration between the stakeholders to address the problem of slum growth. The presence of regular in-kind incentives such as funding from the Ghana government, the Shack and Slum Dwellers International (SSDI), and other international donor NGOs encouraged and sustained other relevant stakeholders such as the Kayayo Youth Association (KYA) and women savings groups to commit themselves and participate meaningfully in the deliberation process. The initial high levels of trust, cooperation and commitment motivated the coming together of participants to agree on a common plan of action to reduce slum growth and improve the lives of poor slum dwellers. As one resident put it "the continual financial support from government and its commitment towards improving the lives of slum inhabitants coupled with the support from the Shack and Slum Dwellers International (SSDI) meant that those stakeholders who are engaged in the negotiation process had greater motivation to share information and other resources to make meaningful improvements in the communities other than symbolic commitment" (Interview, 2014). This study concludes that there is strong, need-centered representative inclusion of local slum dwellers that have the capacity to consolidate and use resources in the creation of new development options for safe, secure and decent shelter conditions in the PSUPS project. The conclusion drawn from many of our interviewees was that the inclusion and participation of relevant and affected actors and the genuine commitment of the lead NGOs, the SSDI and the government there were substantial success the PSUPS project has achieved in terms of improving the living conditions of slum dwellers in the Ga Mashie and Old Fadama communities. To summarize, the initiation and the design process of the PSUPS network process brought about high level of trust, improved relationships among the stakeholders through the awareness the programme created, and finally generated effective action due to the presence of in-kind incentives and cooperative approaches which motivated local residents and other stakeholders to come to the deliberation and negotiation table.

\section{The process designing inclusive participation and representation of relevant stakeholders}

The study findings reveal that non-state actors and civic society organizations, and environmental interest groups have representations in both PSUPS and GRMA projects. Nonetheless, the respondents reported a lack of genuine participation in decision-making and the negotiation processes. Although there were satisfactory levels of local residents and interest groups participation, many of the respondents pointed out in both cases of under representation of women groups and other relevant environmental interest groups and government stakeholders. For example, the Environmental Protection Agency (EPA) input in the design and implementation of environmental sustainability programs was very minimal. Although there was little reliable and detailed demographic data of the study communities in both projects, lack of equality in representation of most affected and disadvantaged interests such as women in slum communities and farmers in mining communities were proportionally smaller the men and the NGOs in the governance process. These gaps in local environmental interest groups, women and farmers and other local government bodies' engagement in the planning and setting of action plans affected the inclusive implementation of targets especially in the GRMA project.

A third participation and inclusive governance limitation respondents in both cases consistently pointed out to was related to the inability to obtain a rough balance of all relevant and affected actors. It was observed that in the entire two network programmes lacked any significant representation outside the already active networked stakeholders (Interview, 2014 Asutifi District). Despite these participation and representation lapses, a positive finding from both projects was the significant success in creating the awareness and the platform for local residents to hold duty bearers accountable through their symbolic inclusion and participation. For example, most slum dwellers and farmers had no previous connection to organized community groups or influence over any decision-making regarding slum upgrading and environmental standards and performance mining companies should observe. As one community resident put it prior to the establishment of the GRMA project "community residents had little or no knowledge at all about any EPA regulations and standards, building permits requirements, noise limits and the responsible mining principles mining companies should observe.

\section{The process of enhancing deliberative decision-making}

Policy formulation and implementation in both PSUPS and the GRMA projects involved multiple private NGOs and public stakeholders as well as community and other civil society organizations engaging in complex and continuous negotiation, deliberation and mediation processes to reach agreement on the most suitable and implementable policy targets. Throughout author study, it was revealed that the presence of more skilled and resource endowed NGOs and industry players ensured that the few women, farmers and local government bodies and actors had little opportunities to express their opinion and influence the decision-making process. The under representation of most disadvantaged women and farmers sufficiently created imbalance in skills, capacities and local knowledge and experiences and this affected the development of comprehensive targets to enhance the living conditions of slum dwellers and farmers in mining communities. Respondents consistently raised concerns about the problem of power imbalances in the governance process and this ultimately undermined the input of local residents and local 
Page 7 of 8

government bodies and only saw the NGOs and the industry players with resources and technical capacities dominate to decision-making process. Although the nature of the deliberative decision-making was observed by examining how often local residents, government and non-government actors were at the negotiation table to solutions to complex developmental challenges based on their own experiences, resource and knowledge, one key interest to the study was examining how the negation and decision-making process between these actors have been. That is how problematic these complex interactions and negotiations between non-government organizations, community stakeholders, government and industry players have been. It was revealed in both programmes that, their decision-making processes had sometimes being associated with conflicts and self-aggrandizing interests bargaining stands. The respondents pointed out as a result of the power imbalances between the participating stakeholders (Interview, 2014). The fair and genuine deliberative governance principle in network governance which to seeks to open up and include all diverse interests and views irrespective of the power base was questioned by many respondents.

The results is that the technical knowledge, skills and capacities as well as other monetary resources possessed by the lead NGOs and the mining companies and their over representation of stakeholders in the deliberative process often overrides and marginalized local community participants. This was most evident in the GRMA project where respondents describe the decision-making, plan policy actions, target writing, consultation and monitoring process as mainly the responsibility of the power wielders in the network (Interview, 2014, Asutifi District Assembly). The conclusion to be drawn from both cases suggest that it is highly impossible for local community stakeholders to influence policy outcomes and underrepresented women groups, unskilled farmers and uninformed local government bodies felt they are just symbolic participants as they could not influence policy decisions and its implementation.

\section{The process of enhancing horizontal accountability}

The findings revealed that although local community stakeholders and local government bodies had little influence over policy decisions and targets setting, the stakeholder oversight, the creation and existence of monitoring and evaluation teams as well as the complementary interaction among stakeholders ensured that performance can easily be assessed and monitored. Although these innovative horizontal performance-based accountability mechanisms did reduce abuse of power significantly, it ensured that the local stakeholders hold duty bearers accountable with regards to funds and resource appropriation (Interview, 2014 Local resident). This ensured the attainment of some level of success in both cases. However, it was revealed that these horizontal accountability mechanisms to ensure local ownership of development projects were more effective in the PSUPS compared to the GRMA. It was reported that in the PSUPS project the evaluation and monitoring team adequately performed their duties and besides that designed adequate and reasonable management control systems to ensure that set targets are met within reasonable time limits. As reported by one respondent, the PSUPS have developed its own management plans to make sure funds are directed towards planned projects. Additionally, programme evaluators monitor subsequent plan projects implemented to ensure that the network follow in great detail the governance processes and the recommendations of the evaluation team (Interview, 2014).
Unlike the PSUPS, the GRMA monitoring and evaluation of implemented targets was very weak and infrequent. As one respondent reported "the cost and technical skills associated with collecting credible data about plans implemented and its impacts posed a serious challenge in the GRMA programme" (Interview, 2014). Mutual interaction and accountability was also reported to be limited hence there were always a mismatch between targets plans set and the knowledge, experiences and resources needed to carry them out. In comparatively terms, the consistent interaction and mutual accountability between stakeholders and the slum communities in the case of PSUPS ensured significant success in securing descent housing facilities and portable drinking water to slum communities. Relatedly, it was observed that the existence of credible data about slum communities through enumeration, profiling and mapping ensured the network reached credible and achievable verifiable targets. Compared to the GRMA the availability of data and adequate knowledge and clear understanding and experiences about slum development gave the network the opportunity to set demonstrable and achievable programs to improve the living conditions in slum communities.

\section{The process of building future cooperation through learning and adaptation}

The findings on this variable revealed that the PSUPS project has developed adequate and an improved structures and capacity in developing workable solutions to slum and other environmental problems in a more reflexive and strategic manner than the GRMA project. As reported during the interview, the savings and group formation, peer to peer exchanges, enumeration, mapping and profiling as well as dialogue and partnership building had ensure to develop the local residents capacities to advocate and influence policies that affect their daily life (Interview, 2014). In particular, respondents in the slum communities reported that the PSUPS governance processes had allowed the network stakeholders especially the slum communities more sensitized to the problem of slums, and the risks to their social and economic well-being.

This has also ensured continual learning about slum impacts and the subsequent demonstrable projects to reduce further slum development. In addition, the stakeholders long-term involvement in the governance process had reportedly served to improved their self-regulatory skills and capacities in target setting, planning and risk analysis. Additionally, this had ensured the continuous search for demonstrable and implementable projects and plans to reduce slum growth and improve the living conditions of slum dwellers as compared to the GRMA project. Through observation, it was discovered that this process-based approach to learning was adequately instituted in the GRMA project. Author observations were further confirmed by the interview data where respondents highlighted the general lack of stakeholder commitment especially the mining companies towards environmental standards which has translated into a strong reluctance to build local capacities to advocate and influence policy decisions.

\section{Conclusion}

It has been established that networks are more likely to be effective in policy settings where negotiated solutions among stakeholders are seen as appropriate and necessary, and thus where technical solutions are not possible. Additionally, Robert Agranoff and Michael McGuire have emphasized the capacity of governance networks in bringing innovation in the public sector yet they highlighted the issue of 
collaborative 'effectiveness' which is fundamental but has been incompletely addressed [20]. Sabatier et al. argues that the governance network literature tends to focus on the inclusion and participation of all affected stakeholders like resource-users and local community actors under natural resource management; this paper revolves around exploring the conditions and mechanisms that affect the performance governance network with the aim of identifying the benchmarks to evaluate the success or failure of governance networks in the land resource and mining sector of Ghana [1]. The discussion shows how the "process" of forming governance network affects its performance. The conclusion drawn from this study is that though networking governance has enormous capacities as a result of the different knowledge, expertise, resources, and skills the different stakeholders bring on board to address complex sets of interconnected environmental problems; the mechanisms for fostering and ensuring effective collaboration, participation, deliberations, accountability, and learning largely affect for the relative success or failure of governance networks. In ensuring these critical requirements are met therefore requires the willingness of the stakeholders especially the network managers to address the restraints regarding these issues which appears to paralyze trust and donor support. Civil society organizations, such as local interest groups and small-scale miners associations, are also seen as potentially fruitful stakeholders who possess diverse local knowledge and authority. The ability of the network managers to strategically include all these stakeholders and providing equal platform for deliberations are found to be critical in building successful governance network for delivering sustainable environmental results.

\section{References}

1. Sabatier P, Focht W, Lubell M, Trachtenberg Z, Vedlitz A, et al. (2005) Collaborative Approaches to Watershed Management. In: Sabatier $\mathrm{P}$, Focht W, Lubell M, Trachtenberg Z, Vedlitz A, et al. Swimming Upstream: Collaborative Approaches to Watershed Management, MIT Press, Cambridge.

2. Cross R, Laseter T, Parker A, Velasquez G (2004) Assessing and Improving Communities of Practice with Organizational Network Analysis. In The Network Roundtable at the University of Virginia. University of Virginia, Stanford University, Halliburton.

3. Sorensen E, Torfing J (2009) Making governance networks effective and democratic through metagovernance. Pub administr 87: 234-258.
4. Jessop B (2000) The Network Society, New Forms of Governance, and Democratic Renewal. Unpublished paper, Copenhagen: COS.

5. Provan KG, P Kenis (2007) Modes of Network Governance: Structure Management and Effectiveness. Journal of Public Administration Research and Theory 18: 229-252.

6. Jessop B (1998) The rise of governance and the risks of failure: the case of economic development. Int Social Sci J 50: 29-45.

7. Kickert, Klijn, Koppenjan (1997) Introduction: A Management Perspective on Policy Network. In: Klijn K, Koppenjan (eds.) Managing Complex Networks.

8. Patton MQ (2002) Qualitative Research and Evaluation Methods 3rd edition SAGE Publications.

9. Rhodes RAW (2007) Understanding Governance: ten year on Organization Studies pp: 1243-1264.

10. Peters BG, Pierre J (2000) Governance Politics and the State Basingstoke: Macmillan.

11. Newig J, Gunther D, Pahl-Wostl C (2010) Synapses in the network: learning in governance networks in the context of environmental management. Ecol Soc 15: 24.

12. Streck C (2002) Global Public Policy Networks as Coalitions for Change. In DC Esty, MH Ivanova, Global Environmental Governance, Options and Opportunities, Yale School of Forestry and Environmental Studies. New Haven.

13. Dedeurwaerdere T (2007) The contribution of network governance to sustainability impact assessment, in Participation for sustainability in trade. pp: 209-228.

14. Haas PM (2004) Addressing the global governance deficit. Global Environ Polit 4: 1-15.

15. Head BW (2008) Assessing network-based collaborations: effectiveness for whom? Public Manage Rev 10: 733-749.

16. Provan KG, Milward HB (2001) Do Networks Really Work? A Framework for Evaluating Public Sector Organizational Networks. Public Administration Review 61: 414-423.

17. Connell JP, Kubisch AC, Schorr LB, Weiss CH (1995) New Approaches to Evaluating Community Initiatives, New York: Aspen Institute.

18. Schorr LB (2003) Determining 'What Works' in Social Programs and Social Policies: Toward a More Inclusive Knowledge Base. Brookings, Washington DC.

19. Coglianese C (2002) Is Satisfaction Success? Evaluating Public Participation in Regulatory Policy-Making. pp: 1-27.

20. Agranoff RI, McGuire M (2003) Collaborative Public Management: New Strategies for Local Government. Washington DC: Georgetown University Press. 